\title{
COVID-19 mortality in cancer patients: a report from a tertiary cancer centre in India
}

\author{
Anurag Mehta ${ }^{1}$, Smreti Vasudevan ${ }^{\text {Corresp., }}{ }^{2}$, Anuj Parkash ${ }^{\text {Corresp., }}{ }^{3}$, Anurag Sharma ${ }^{2}$, Tanu Vashist ${ }^{2}$, Vidya Krishna ${ }^{2}$ \\ 1 Department of Laboratory, Transfusion and Molecular Diagnostics Services, Rajiv Gandhi Cancer Institute \& Research Centre, DELHI, Delhi, India \\ 2 Department of Research, Rajiv Gandhi Cancer Institute \& Research Centre, DELHI, Delhi, India \\ 3 Department of Laboratory and Transfusion Services, Rajiv Gandhi Cancer Institute \& Research Centre, DELHI, Delhi, India \\ Corresponding Authors: Smreti Vasudevan, Anuj Parkash \\ Email address: smreti@gmail.com,dranujpa@gmail.com
}

Background: Cancer patients, especially those receiving cytotoxic therapy, are assumed to have a higher probability of death from COVID-19. We have conducted this study to identify the Case Fatality Rate (CFR) in cancer patients with COVID-19 and have explored the relationship of various clinical factors to mortality in our patient cohort. Methods: All confirmed cancer cases presented to the hospital from June 8 to August 20, 2020, and developed symptoms/ radiological features suspicious of COVID-19 were tested by Realtime polymerase chain reaction assay and/or cartridge-based nucleic acid amplification test from a combination of naso-oropharyngeal swab for SARS-CoV-2. Clinical data, treatment details, and outcomes were assessed from the medical records. Results: Of the total 3101 cancer patients admitted to the hospital, 1088 patients were tested and 186 patients were positive for SARS-CoV-2. The CFR in the cohort was 27/186 (14.52\%). Univariate analysis showed that the risk of death was significantly associated with the presence of any comorbidity [OR: 2.68 ; $(95 \% \mathrm{Cl}: 1.13-6.32) ; P=0.025]$, multiple comorbidities [OR: $3.01 ;(95 \% \mathrm{Cl}: 1.02-9.07) ; P=0.047$ for multiple vs. single], and the severity of COVID-19 presentation [OR: 27.48; (95\%Cl: 5.34-141.49); $P<0.001$ for severe vs. not severe symptoms]. Among all comorbidities, diabetes [OR: 3.31; $(95 \% \mathrm{Cl}$ : 1.35-8.09); $P=0.009$ ] and cardiovascular diseases [OR: 3.77; $(95 \% \mathrm{Cl}: 1.02-13.91)$; $P=0.046]$ were significant risk factors for death. Anticancer treatments including chemotherapy, surgery, radiotherapy, targeted therapy, and immunotherapy administered within a month before the onset of COVID-19 symptoms had no significant effect on mortality. Conclusion: To the best of our knowledge, this is the first study from India reporting the CFR, clinical associations, and risk factors for mortality in SARS-CoV-2 infected cancer patients. Our study shows that the frequency of COVID-19 in cancer patients is high. Recent anticancer therapies are not associated with mortality. Pre-existing comorbidities, especially diabetes, multiple comorbidities, and severe symptoms at 
presentation are significantly linked with COVID-19 related death in the cohort. 
1 COVID-19 Mortality in Cancer Patients: A Report from a Tertiary Cancer Centre in India

2 Abstract

3 Background: Cancer patients, especially those receiving cytotoxic therapy, are assumed to have 4 a higher probability of death from COVID-19. We have conducted this study to identify the Case

5 Fatality Rate (CFR) in cancer patients with COVID-19 and have explored the relationship of

6 various clinical factors to mortality in our patient cohort.

7 Methods: All confirmed cancer cases presented to the hospital from June 8 to August 20, 2020,

8 and developed symptoms/ radiological features suspicious of COVID-19 were tested by Real9 time polymerase chain reaction assay and/or cartridge-based nucleic acid amplification test from a combination of naso-oropharyngeal swab for SARS-CoV-2. Clinical data, treatment details, and outcomes were assessed from the medical records.

Results: Of the total 3101 cancer patients admitted to the hospital, 1088 patients were tested and 186 patients were positive for SARS-CoV-2. The CFR in the cohort was 27/186 (14.52\%). Univariate analysis showed that the risk of death was significantly associated with the presence of any comorbidity [OR: 2.68; (95\%CI: 1.13-6.32); $P=0.025]$, multiple comorbidities [OR: 3.01; (95\%CI: 1.02-9.07); $P=0.047$ for multiple vs. single], and the severity of COVID-19 presentation [OR: 27.48; (95\%CI: 5.34-141.49); $P<0.001$ for severe vs. not severe symptoms]. Among all comorbidities, diabetes [OR: 3.31; $(95 \% \mathrm{CI}$ : 1.35-8.09); $P=0.009]$ and cardiovascular diseases [OR: 3.77; (95\%CI: 1.02-13.91); $P=0.046]$ were significant risk factors for death. Anticancer treatments including chemotherapy, surgery, radiotherapy, targeted therapy, and immunotherapy administered within a month before the onset of COVID-19 symptoms had no significant effect on mortality.

Conclusion: To the best of our knowledge, this is the first study from India reporting the CFR, clinical associations, and risk factors for mortality in SARS-CoV-2 infected cancer patients. Our study shows that the frequency of COVID-19 in cancer patients is high. Recent anticancer therapies are not associated with mortality. Pre-existing comorbidities, especially diabetes, multiple comorbidities, and severe symptoms at presentation are significantly linked with COVID-19 related death in the cohort. 


\section{Introduction}

30 The ongoing pandemic of coronavirus disease 2019 (COVID-19) caused by severe acute 31 respiratory syndrome coronavirus 2 (SARS-CoV-2) has caused unprecedented health and 32 societal crises across the globe. However, this catastrophe has victimized the cancer patients the 33 most, adversely impacting diagnosis and treatment in about 55\% of cases worldwide (WHO, 2020). The number of patients visiting and accessing oncological services has considerably reduced and the collateral damage can have an adverse impact on cancer outcomes (Guven et al. 2020; Sud et al. 2020). It is generally assumed that patients with cancer are at a higher risk of contracting COVID-19 due to their immunosuppressive state, and side effects associated with anticancer therapies like leukopenia and disruption of the barrier to infections (ElGohary et al. 2020; Ganatra et al. 2020; Liang et al. 2020). Additionally, it is also postulated that the severity and resulting mortality is amplified in cancer patients with COVID-19 due to their elderly and the immunocompromised state further worsened by cancer treatment. Multiple studies from different geographical locations show that the case fatality rate (CFR) of the SARS-CoV-2 infected cancer patients varies from 3.7\% to 61.5\% (He et al. 2020; Kalinsky et al. 2020; Saini et al. 2020). Despite recent efforts, no clear consensus has been reached for the relation of mortality to demographics, cancer type, stage, and underlying comorbidities; and it may depend on the epidemiology and prevalent oncology practices (Miyashita et al. 2020; Oh 2020). Various studies regarding the risk of treating cancer patients during the pandemic have shown contradictory results (Dai et al. 2020; Lee et al. 2020; Liang et al. 2020; Pinato et al. 2020). Larger datasets acquired globally from different sources and geographic locations and rationally analyzed has the best potential to provide an effective risk-benefit calculus to assist oncologists to optimize the management and use anticancer treatments to restore outcomes to the pre-COVID 19 era. 
52 We aim to describe the clinical and demographic characteristics and COVID-19 outcomes in a 53 cohort of patients with cancer and symptomatic COVID-19. An attempt has also been made to 54 assess the adverse effect of cytotoxic and other novel therapies on mortality in cancer patients 55 with COVID-19.

Materials and Methods

Study design and subjects: The study is single-center, retrospective, conducted at a tertiary cancer care hospital. Patients with active cancer presented to the hospital between June 8 to August 20, 2020, and with confirmed COVID-19 infection were included. Clinical data, anticancer treatment details (performed within a month of COVID-19 diagnosis), clinical course, and outcome were retrieved from the hospital electronic medical records. The COVID-19 infection severity of patients was scored at the time of presentation by the treating physician, according to the Ministry of Health and Family Welfare (Government of India) guidelines (MoHFW, 2020; MoHFW version 3, 2020).

The study has been approved by our Institutional Review Board (RGCIRC/IRB-BHR/61/2020) and was conducted according to the Declaration of Helsinki.

Real-Time Polymerase Chain Reaction assay: According to the Indian Council of Medical Research (ICMR) guidelines and international practice, the COVID-19 symptomatic cancer patients were tested by Real-Time Polymerase Chain Reaction (RT-PCR) assay and/or cartridgebased nucleic acid amplification test (CBNAAT) test for SARS-CoV-2. 
73 Samples were collected from the nasopharynx and oropharynx in a single tube with $3 \mathrm{ml}$ of the 74 viral transport medium (Biogenix ${ }^{\circledR}$ Lucknow - 226012, Uttar Pradesh, India). The RT-PCR test was carried out on the QuantStudio ${ }^{\text {TM }} 5$ Real-Time PCR System (Thermo-Fishers Scientific-Life

76 Technologies Holdings Pvt. Ltd., Block 33, Marsiling Industrial Estate Road 3, Singapore 77 739256) employing an ICMR approved RT-PCR test kit (TRUPCR ${ }^{\circledR}-3 B$ BlackBio Biotech, 78 Govindpura, Bhopal, Madhya Pradesh 462023, India). This kit detects the E gene common to the 79 Sarbecovirus superfamily, a sampling control of human ribonucleic acid nuclease P (hRNaseP) and RNA dependent RNA polymerase (RdRP) gene, and N gene for the detection of SARSCoV-2. The test was performed and interpreted as per the manufacturer's instructions.

In certain cases, rapid molecular testing was used utilizing a cartridge-based nucleic acid testing (CBNAAT) from Cepheid ${ }^{\circledR}$ USA, Sunnyvale, CA 94089, United States (GeneXpert ${ }^{\circledR}$ assay). It identifies E gene-specific RNA and N2 gene-specific RNA. The test was performed and interpreted as per the downloaded package insert.

Statistical Analysis: Continuous variables were presented as mean \pm standard deviation (SD) or median (interquartile range, IQR). Categorical variables were presented as frequencies and percentages. The two-sided independent t-test and the median test were used to compare the mean and median ages, respectively. Fisher's exact test/ Pearson's Chi-Squared test was used to compare categorical data. Univariate logistic regression was used to estimate odds ratio (OR) and 95\% confidence intervals (CI). Multivariate logistic regression was used to compute the odds ratio for the various treatment modalities after adjusting for age and comorbidities. All the statistical analyses have been performed either by using SPSS ${ }^{\circledR}$ Version 23.0 software or MedCalc Statistical Software version 19.4.0. The reported $P$ values are two-sided and a $P$ value $<0.05$ was considered statistically significant. 


\section{Results}

98 A total of 3101 cancer patients were treated at the indoor facility of the center. One thousand and 99 eighty-eight patients developed signs, symptoms, and/ or radiological features suspicious of COVID-19. Of these, 186 tested positive for COVID-19 and formed the study cohort. The infection rate of COVID-19 among all cancer patients treated at the center was $\sim 6 \%(186 / 3101)$ and $17.1 \%(186 / 1088)$ of the symptomatic and tested cancer patients. The clinical features are shown in Table 1. Most patients had solid malignancies (82.26\%); gastrointestinal cancer (21.51\%) was the most common cancer type, and about $17.74 \%$ of cases presented with hematological malignancies. More than a quarter of cases $(26.88 \%)$ were metastatic. Eighty-six patients (46.24\%) had at least a single comorbidity; hypertension (24.19\%) and diabetes $(18.28 \%)$ were the most common. About $60 \%$ of cases were on active cancer treatment and had received cancer-directed treatment within a month before the onset of COVID-19 symptoms. The majority of patients were on chemotherapy (37\%).

The chief presenting symptoms of SARS-CoV-2 infection were fever $(123 / 186,66.13 \%$, fatigue (26/186, 13.98\%) and respiratory distress $(25 / 186,13.44 \%)$. Around 5\% of patients were

112 presented with severe disease. The COVID-19 associated fatality rate in the cohort was $14.52 \%$ 113 (27/ 186) [median follow-up duration: 63 days]. Compared to hospitalized cancer patients 114 without COVID-19, the CFR in cancer patients with COVID-19 was significantly higher 115 (27/186, 14.32\% vs. 40/2915, 1.37\%; $P<0.0001)$. The CFR for hematological malignancies 116 tended to be higher than the CFR for solid malignancies, however, the difference did not reach 117 statistical significance $(7 / 33,21.21 \%$ vs. $20 / 153,13.07 \%, P=0.274)$. 
118 Severe COVID-19 infected cancer cases were managed by treatments including corticosteroids,

119 hydroxychloroquine, remdesivir, tocilizumab and convalescent plasma therapy. Patients with

120 mild or moderate disease severity were given symptomatic treatment. Hydroxychloroquine and/

121 or dexamethasone were administered in moderate disease severity cases. Assisted ventilation was

122 given to 12 patients (6.45\%), however, all of these patients eventually developed COVID-19

123 related complications like pneumonitis and associated respiratory failure, septic shock, or sudden

124 cardiac arrest and succumbed to the disease.

125 Next, we explored the differences between the cancer patients who died and those who survived 126 the SARS-CoV-2 infection (Table 1). There was no significant difference between the survivors 127 and the non-survivors with respect to age, gender, type of malignancy, and cancer spread. Also, 128 no significant effect on mortality was noted for the patients who had received anticancer therapy 129 within the past month. Deceased patients displayed significantly higher rates of comorbidity 130 compared to the cancer patients who survived $(66.67 \%$ vs. $42.77 \%, P=0.035)$; patients with 131 greater than one comorbidity had significantly inferior outcome than those with single or no 132 comorbidity $(P=0.004)$. Importantly, patients with diabetes experienced significantly more 133 deaths than patients without diabetes $(P=0.013)$ (Table 1). Further, we observed that cancer 134 patients presented with moderate or severe COVID-19 symptoms had significantly higher mortality than those presented with mild symptoms $(P<0.00001)$.

136 The univariate logistic regression analysis for death has been shown in Table 2. The mortality 137 risk was statistically significant for the presence of any comorbidity $[\mathrm{OR}=2.68, P=0.025]$, 138 multiple vs. single morbidity [OR=3.01, $P=0.047$, cardiovascular disease [OR=3.77, $P=0.046]$ 139 and diabetes $[\mathrm{OR}=3.31, P=0.009]$. The odds of death were significantly higher in patients 140 presented with severe COVID-19 infection symptoms compared to mild/moderately 
141 symptomatic patients $(\mathrm{OR}=27.48, P<0.001)$. Patients who were on active cancer treatment

142 during one month before contracting COVID-19 did not have an increased risk of death

$143(P=0.460)$. Also, the treatment modalities including surgery, chemotherapy, radiotherapy,

144 targeted therapy, and immunotherapy did not confer an increased risk of death in univariate

145 analyses. There was a significant difference in the median age of the patients who received

146 chemotherapy compared to those who did not (49 years vs. 54 years, $P=0.005$ ). So we further

147 examined whether anticancer therapies could influence mortality in the cohort by adjusting for

148 age and comorbidity in the multivariate logistic regression analysis (Table 3 ). In comparison to

149 the patients who were not on these treatments, there were no significant increase in risk of death

150 with chemotherapy $(\mathrm{OR}=1.63,95 \% \mathrm{CI}: 0.64-4.15, P=0.301)$, radiotherapy $(\mathrm{OR}=0.19,95 \% \mathrm{CI}$ :

$1510.02-1.59, P=0.126)$, targeted therapy $(\mathrm{OR}=2.70,95 \% \mathrm{CI}: 0.42-17.37, P=0.296)$, immunotherapy

$152(\mathrm{OR}=0.40,95 \% \mathrm{CI}: 0.04-3.56, P=0.413)$, or surgery $(\mathrm{OR}=0.87,95 \% \mathrm{CI}: 0.25-2.94, P=0.819)$

153 (Table 3).

154 Discussion

155 The COVID-19 pandemic has raised several fears. One of these has been the increased risk of 156 cancer patients to contract COVID-19. In the current study, we found the incidence of COVID-

15719 to be $\sim 6.0 \%$ in our hospitalized cancer patients. The national incidence of COVID-19 in an 158 unselected cohort is $0.32 \%$ and $0.29 \%$ as per the European Centre for Disease Prevention and 159 Control (Figure 1a) (Aarogya Setu Mobile App. 2020; Roser et al. 2020). The incidence of 160 COVID-19 observed in hospitalized cancer patients is expected to be higher than in the general 161 population. This on the one hand can be ascribed to patients' factors, visitations, and admission 162 to a health care facility with a high risk of contracting infection; may also be partly because of 163 lower case detection rates in the general population in India due to poor access to health care 
164 facilities and low testing rates. The reported incidence in other high COVID-19 incidence

165 nations like Brazil and the USA, and other middle and low incidence countries have been shown 166 in Figure 1b.

167 The average CFR of COVID-19 is $1.9 \%$ in the unselected Indian population as per the national 168 database (Arogyasetu Application), 1.84\% by Johns Hopkins COVID-19 tracker, and 1.7\% as 169 per the European Centre for Disease Prevention and Control (Figure 1c) (Aarogya Setu Mobile 170 App. 2020; John Hopkins Corona Virus Resource Center, 2020; Roser et al. 2020). The 14.52\% 171 COVID-19 related CFR observed for hospitalized cancer patients in the present study is similar 172 to the data reported by Ma et al. from Renmin Hospital of Wuhan University (CFR-13.5\%), and 173 is higher than a recent report from Tata Memorial Hospital, Mumbai, India (CFR-6.5\%) (Ma et al. 2020; Ramaswamy et al. 2020). The previous studies from the European continent have also 175 shown a far greater CFR in cancer patients with COVID-19. In the UK Coronavirus Cancer 176 Monitoring Project (UKCCMP), a CFR of 30.6\% was observed, where 319 of the 1044 cancer 177 patients with COVID-19 died with 92.5\% had their death attributed directly to COVID-19 (Lee 178 et al. 2020). In another observational study by Pinato et al. of 890 cancer patients diagnosed with 179 SARS-CoV-2, mortality was found to be 33.6\% (Pinato et al. 2020). Similarly, high rates were 180 noticed in a New York Hospital System where a CFR of 28\% was observed (Mehta et al. 2020). A large systematic review of 52 studies by a group led by Kamal S Saini involving more than 18,000 cases of cancer with COVID-19, the probability of death was $25 \cdot 6 \%(95 \%$ CI $22 \cdot 0 \%$ to $29 \cdot 9 \% ; I^{2}=48 \cdot 9 \%$ ) (Saini et al. 2020). Among the hospitalized cancer patients, we observed that

184 the CFR was about 10.6 times higher in the COVID-19 infected patients than those without 185 COVID-19 (14.52\% vs. $1.37 \%, P<0.0001)$ indicating that COVID-19 infection significantly 186 increased the risk of death in the cohort. 
187 Unlike the previous retrospective studies from China, we did not find any significant association

188 between recent cancer treatments and mortality (Dai et al. 2020; Liang et al. 2020). Our

189 observation is in line with two large cohort studies conducted by Lee et al. on 800 COVID-19

190 positive cancer patients from UKCCMP, and by Robilotti et al. on 423 symptomatic COVID-19

191 cancer patients at Memorial Sloan Kettering Cancer Centre in New York (Lee et al. 2020;

192 Robilotti et al. 2020). The recent multi-center study by Pinato et al. in the European cancer

193 patients and the Covid-19 and Cancer Consortium (CCC19) database study also strengthens the

194 notion that cancer treatment is not associated with mortality (Kuderer et al. 2020; Pinato et al.

195 2020). Similar to these studies we found that it is the underlying comorbid conditions and

196 COVID-19 disease severity that are associated with adverse outcomes. Consistent with the

197 CCC19 study we observed a higher burden of pre-existing comorbidities $(>1)$ to be associated

198 with increased mortality (Kuderer et al. 2020). Cardiovascular diseases and diabetes posed a

199 higher risk of death in our cohort. It should be noted that comorbid conditions like diabetes

200 frequently co-occur with hypertension or coronary artery disease in patients and can further

201 weaken the immune response escalating the risk of death due to COVID-19 (Guan et al. 2020;

202 Naqvi et al. 2017).

203 Conclusion

204 Our study highlights the high rates of COVID-19 in cancer patients, with a CFR of $14.52 \%$.

205 Recent anticancer therapies did not have a significant effect on mortality in the cohort. Pre-

206 existing comorbidities especially diabetes, presence of more than one comorbidity and severe

207 COVID-19 presenting symptoms were significantly linked with COVID-19 related deaths in the 208 cohort. 
210

211

212

213

214

215

216

217

218

219

220

221

222

223

224

225

226

227

228

229

230

231

\section{References}

Aarogya Setu Mobile App. 2020. Government of India. Available at https://www.mygov.in/aarogya-setu-app/(accessed 5 September 2020).

Dai M, Liu D, Liu M, Zhou F, Li G, Chen Z, Zhang Z, You H, Wu M, Zheng Q, Xiong Y, Xiong H, Wang C, Chen C, Xiong F, Zhang Y, Peng Y, Ge S, Zhen B, Yu T, Wang L, Wang H, Liu Y, Chen Y, Mei J, Gao X, Li Z, Gan L, He C, Shi Y, Qi Y, Yang J, Tenen DG, Chai L, Mucci LA, Santillana M, and Cai H. 2020. Patients with Cancer Appear More Vulnerable to SARS-CoV-2: A Multicenter Study during the COVID-19 Outbreak. Cancer Discov 10:783-791. 10.1158/2159-8290.CD-20-0422

ElGohary GM, Hashmi S, Styczynski J, Kharfan-Dabaja MA, Alblooshi RM, de la Camara R, Mohmed S, Alshaibani A, Cesaro S, Abd El-Aziz N, Almaghrabi R, Gergis U, Majhail NS, El-Gohary Y, Chemaly RF, Aljurf M, and El Fakih R. 2020. The risk and prognosis of COVID-19 infection in cancer patients: A systematic review and meta-analysis. Hematol Oncol Stem Cell Ther. 10.1016/j.hemonc.2020.07.005

Ganatra S, Hammond SP, and Nohria A. 2020. The Novel Coronavirus Disease (COVID-19) Threat for Patients With Cardiovascular Disease and Cancer. JACC CardioOncol 2:350355. 10.1016/j.jaccao.2020.03.001

Guan WJ, Liang WH, Zhao Y, Liang HR, Chen ZS, Li YM, Liu XQ, Chen RC, Tang CL, Wang T, Ou CQ, Li L, Chen PY, Sang L, Wang W, Li JF, Li CC, Ou LM, Cheng B, Xiong S, Ni ZY, Xiang J, Hu Y, Liu L, Shan H, Lei CL, Peng YX, Wei L, Liu Y, Hu YH, Peng P, Wang JM, Liu JY, Chen Z, Li G, Zheng ZJ, Qiu SQ, Luo J, Ye CJ, Zhu SY, Cheng LL, Ye F, Li SY, Zheng JP, Zhang NF, Zhong NS, and He JX. 2020. Comorbidity and its 
impact on 1590 patients with COVID-19 in China: a nationwide analysis. Eur Respir J

234

235

236

237

238

Guven DC, Aktas BY, Aksun MS, Ucgul E, Sahin TK, Yildirim HC, Guner G, Kertmen N, Dizdar O, Kilickap S, Aksoy S, Yalcin S, Turker A, Uckun FM, and Arik Z. 2020. COVID-19 pandemic: changes in cancer admissions. BMJ Support Palliat Care. 10.1136/bmjspcare-2020-002468

He W, Chen L, Yuan G, Fang Y, Chen W, Wu D, Liang B, Lu X, Ma Y, Li L, Wang H, Chen Z, Li Q, and Gale RP. 2020. COVID-19 in persons with haematological cancers. Leukemia 34:1637-1645. 10.1038/s41375-020-0836-7

John. John Hopkins Corona Virus Resource Center. 2020. Available at https://coronavirus.jhu.edu/data (accessed 6 September 2020).

Kalinsky K, Accordino MK, Hosi K, Hawley JE, Trivedi MS, Crew KD, and Hershman DL. 2020. Characteristics and outcomes of patients with breast cancer diagnosed with SARSCov-2 infection at an academic center in New York City. Breast Cancer Res Treat 182:239-242. 10.1007/s10549-020-05667-6

Kuderer NM, Choueiri TK, Shah DP, Shyr Y, Rubinstein SM, Rivera DR, Shete S, Hsu CY, Desai A, de Lima Lopes G, Jr., Grivas P, Painter CA, Peters S, Thompson MA, Bakouny Z, Batist G, Bekaii-Saab T, Bilen MA, Bouganim N, Larroya MB, Castellano D, Del Prete SA, Doroshow DB, Egan PC, Elkrief A, Farmakiotis D, Flora D, Galsky MD, Glover MJ, Griffiths EA, Gulati AP, Gupta S, Hafez N, Halfdanarson TR, Hawley JE, Hsu E, Kasi A, Khaki AR, Lemmon CA, Lewis C, Logan B, Masters T, McKay RR, Mesa RA, Morgans AK, Mulcahy MF, Panagiotou OA, Peddi P, Pennell NA, Reynolds K, Rosen LR, Rosovsky R, Salazar M, Schmidt A, Shah SA, Shaya JA, Steinharter J, 

and Warner JL. 2020. Clinical impact of COVID-19 on patients with cancer (CCC19): a cohort study. Lancet 395:1907-1918. 10.1016/S0140-6736(20)31187-9

259

260

261

262

263

264

265

266

267

268

269

270

271

272

273

274

275

276

277

Lee LY, Cazier JB, Angelis V, Arnold R, Bisht V, Campton NA, Chackathayil J, Cheng VW, Curley HM, Fittall MW, Freeman-Mills L, Gennatas S, Goel A, Hartley S, Hughes DJ, Kerr D, Lee AJ, Lee RJ, McGrath SE, Middleton CP, Murugaesu N, Newsom-Davis T, Okines AF, Olsson-Brown AC, Palles C, Pan Y, Pettengell R, Powles T, Protheroe EA, Purshouse K, Sharma-Oates A, Sivakumar S, Smith AJ, Starkey T, Turnbull CD, Varnai C, Yousaf N, Kerr R, and Middleton G. 2020. COVID-19 mortality in patients with cancer on chemotherapy or other anticancer treatments: a prospective cohort study. Lancet 395:1919-1926. 10.1016/S0140-6736(20)31173-9

Liang W, Guan W, Chen R, Wang W, Li J, Xu K, Li C, Ai Q, Lu W, Liang H, Li S, and He J. 2020. Cancer patients in SARS-CoV-2 infection: a nationwide analysis in China. Lancet Oncol 21:335-337. 10.1016/S1470-2045(20)30096-6

Ma J, Yin J, Qian Y, and Wu Y. 2020. Clinical characteristics and prognosis in cancer patients with COVID-19: A single center's retrospective study. $J$ Infect 81:318-356. 10.1016/j.jinf.2020.04.006

Mehta V, Goel S, Kabarriti R, Cole D, Goldfinger M, Acuna-Villaorduna A, Pradhan K, Thota R, Reissman S, Sparano JA, Gartrell BA, Smith RV, Ohri N, Garg M, Racine AD, Kalnicki S, Perez-Soler R, Halmos B, and Verma A. 2020. Case Fatality Rate of Cancer Patients with COVID-19 in a New York Hospital System. Cancer Discov 10:935-941. 10.1158/2159-8290.CD-20-0516 
278 Miyashita H, Mikami T, Chopra N, Yamada T, Chernyavsky S, Rizk D, and Cruz C. 2020. Do

279 patients with cancer have a poorer prognosis of COVID-19? An experience in New York City. Ann Oncol 31:1088-1089. 10.1016/j.annonc.2020.04.006

281

282

283

284

285

286

287

288

289

290

291

292

293

294

295

296

297

298

299

300

MoHFW. Revised Guidelines on Clinical Management of COVID - 19. 2020. Government of India. Ministry of Health \& Family Welfare. Directorate General of Health Services. Dated

31 st

March

2020.

Available

at https://www.mohfw.gov.in/pdf/RevisedNationalClinicalManagementGuidelineforCOVID 1931032020.pdf(accessed 6 September 2020).

MoHFW version 3. Clinical management protocol: COVID-19. 2020. Government of India Ministry of Health and Family Welfare Directorate General of Health ServicesVersion 3 Dated $13 \quad$ June 2020 Available at https://wwwmohfwgovin/pdf/ClinicalManagementProtocolforCOVID19pdf (accessed 6 September 2020).

Naqvi AA, Shah A, Ahmad R, and Ahmad N. 2017. Developing an Integrated Treatment Pathway for a Post-Coronary Artery Bypass Grating (CABG) Geriatric Patient with Comorbid Hypertension and Type 1 Diabetes Mellitus for Treating Acute Hypoglycemia and Electrolyte Imbalance. J Pharm Bioallied Sci 9:216-220. 10.4103/jpbs.JPBS_33_17

Oh WK. 2020. COVID-19 infection in cancer patients: early observations and unanswered questions. Ann Oncol 31:838-839. 10.1016/j.annonc.2020.03.297

Pinato DJ, Zambelli A, Aguilar-Company J, Bower M, Sng C, Salazar R, Bertuzzi A, Brunet J, Mesia R, Segui E, Biello F, Generali D, Grisanti S, Rizzo G, Libertini M, Maconi A, Harbeck N, Vincenzi B, Bertulli R, Ottaviani D, Carbo A, Bruna R, Benafif S, Marrari A, Wuerstlein R, Carmona-Garcia MC, Chopra N, Tondini C, Mirallas O, Tovazzi V, Betti 
301

302

303

304

305

306

307

308

309

310

311

312

313

314

315

316

317

318

319

320

321

M, Provenzano S, Fotia V, Cruz CA, Dalla Pria A, D'Avanzo F, Evans JS, SaoudiGonzalez N, Felip E, Galazi M, Garcia-Fructuoso I, Lee AJX, Newsom-Davis T, Patriarca A, Garcia-Illescas D, Reyes R, Dileo P, Sharkey R, Wong YNS, Ferrante D, Marco-Hernandez J, Sureda A, Maluquer C, Ruiz-Camps I, Gaidano G, Rimassa L, Chiudinelli L, Izuzquiza M, Cabirta A, Franchi M, Santoro A, Prat A, Tabernero J, and Gennari A. 2020. Clinical portrait of the SARS-CoV-2 epidemic in European cancer patients. Cancer Discov. 10.1158/2159-8290.CD-20-0773

Ramaswamy A, Nayak L, Moulik NR, Sengar M, Chinnaswamy G, Jobanputra K, Shah MJ, Kapoor A, Joshi A, Kumar A, Gokarn A, Bonda A, Parambil BC, Prasad M, Bagal B, Dhamne C, Narula G, Jain H, Ghosh J, Thorat J, Bajpai J, Menon N, Khattry N, Bhargava P, Punatar S, Gulia S, Banavali S, Gupta S, Srinivas S, Rath S, Tushar Vora T, Noronha V, Patil VM, Ostwal V, and Prabhash K. 2020. COVID-19 in cancer patients on active systemic therapy - Outcomes from LMIC scenario with an emphasis on need for active treatment. Cancer Medicine https://doi.org/10.1002/cam4.3423.

Robilotti EV, Babady NE, Mead PA, and al. e. 2020. Determinants of COVID-19 disease severity in patients with cancer. Nat Med 26:1218-1223. https://doi.org/1210.1038/s41591-41020-40979-41590.

Roser M, Ritchie H, Ortiz-Ospina E, and Hasell J. Coronavirus Pandemic (COVID-19). 2020. Published online at OurWorldInData.org. Retrived from: https://ourworldindata.org/coronavirus [Online Resource] (accessed on 6th September 2020). 
322 Saini KS, Tagliamento M, Lambertini M, McNally R, Romano M, Leone M, Curigliano G, and

323

324

325

326

327

328

329

330

331

332

333

334

335

336

337

338 de Azambujag E. 2020. Mortality in patients with cancer and COVID-19: A systematic review and pooled analysis of 52 studies. Eur J Cancer doi: 10.1016/j.ejca.2020.08.011.

Sud A, Jones ME, Broggio J, Loveday C, Torr B, Garrett A, Nicol DL, Jhanji S, Boyce SA, Gronthoud F, Ward P, Handy JM, Yousaf N, Larkin J, Suh YE, Scott S, Pharoah PDP, Swanton C, Abbosh C, Williams M, Lyratzopoulos G, Houlston R, and Turnbull C. 2020. Collateral damage: the impact on outcomes from cancer surgery of the COVID-19 pandemic. Ann Oncol 31:1065-1074. 10.1016/j.annonc.2020.05.009

World Health Organisation. 2020. The impact of the COVID-19 pandemic on noncommunicable disease resources and services: Results of a rapid assessment. Available at https://wwwwhoint/publications/i/item/ncds-covid-rapid-assessment (accessed

3
September 2020). 
Figure 1 (on next page)

Figure 1

Figure 1 (a-c). Incidence and fatality due to COVID-19 in the population (a) Cumulative COVID-19 incidence per million population (India). (b) The incidence of COVID 19 in general population ranges from $1.9 \%$ in Brazil to $0.13 \%$ in Pakistan. (c) The COVID-19 Case Fatality Rate in India is 1.7\%. Source: European Centre for Disease Prevention and Control (Data as on September 6, 2020) ${ }^{(14)}$ 
Figures

Figure $1(\mathrm{a}-\mathrm{c})$. Incidence and fatality due to COVID-19 in the population (a) Cumulative COVID19 incidence per million population (India). (b) The incidence of COVID 19 in general population ranges from $1.9 \%$ in Brazil to $0.13 \%$ in Pakistan. (c) The COVID-19 Case Fatality Rate in India is $1.7 \%$.

Source: European Centre for Disease Prevention and Control (Data as on September 6, 2020) ${ }^{(14)}$

(a)

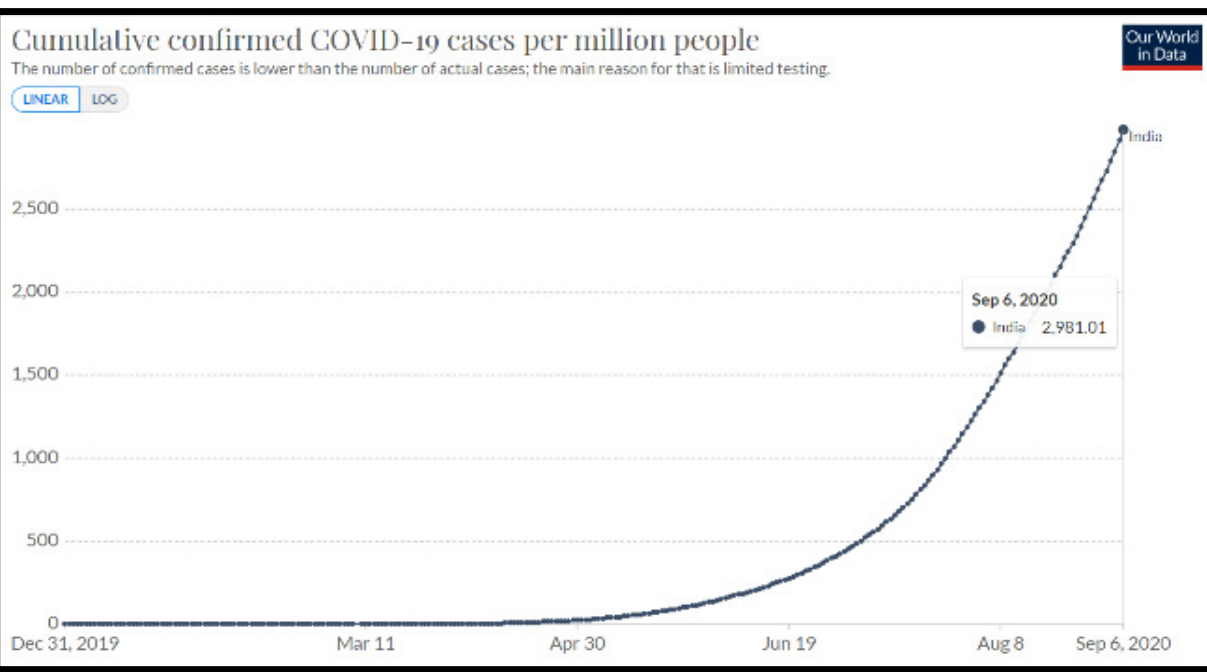

(b)

Cumulative confirmed COVID-19 cases per million people The number of confirmed cases is lower than the number of actual cases; the main reason for that is limited testing. LINEAR LOG

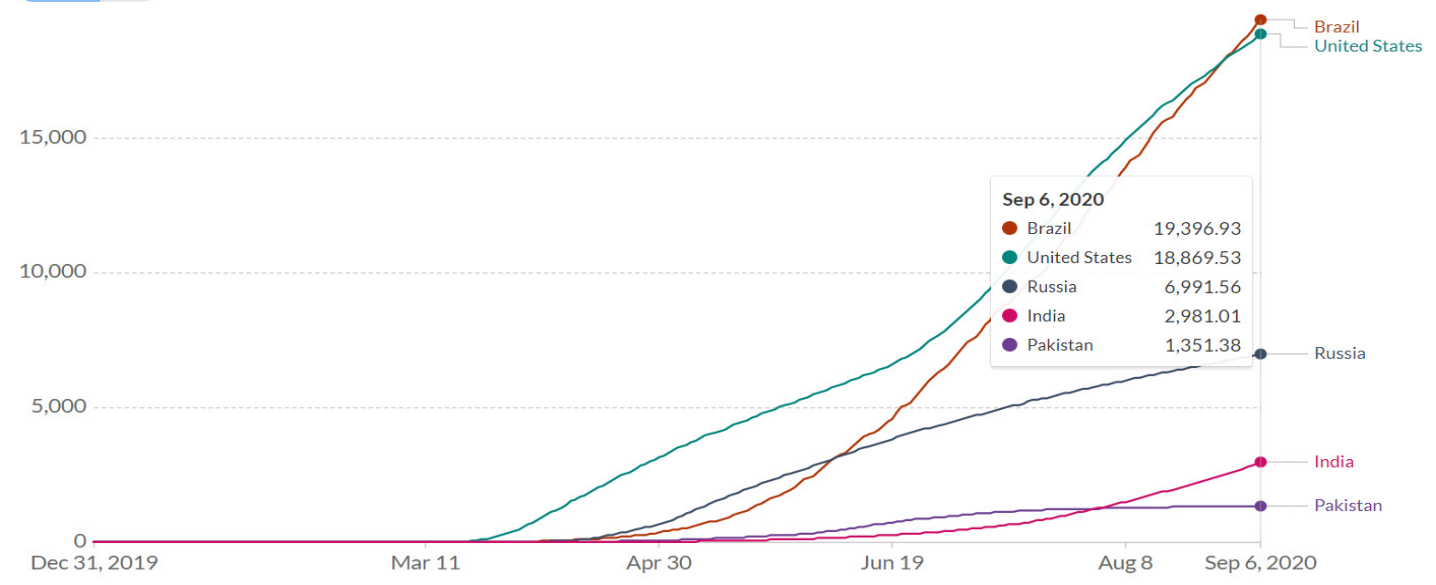


(c)

Case fatality rate of the ongoing COVID-19 pandemic

The Case Fatality Rate (CFR) is the ratio between confirmed deaths and confirmed cases. During an outbreak of a pandemic the CFR is a poor

measure of the mortality risk of the disease. We explain this in detail at OurWorldinData.org/Coronavirus

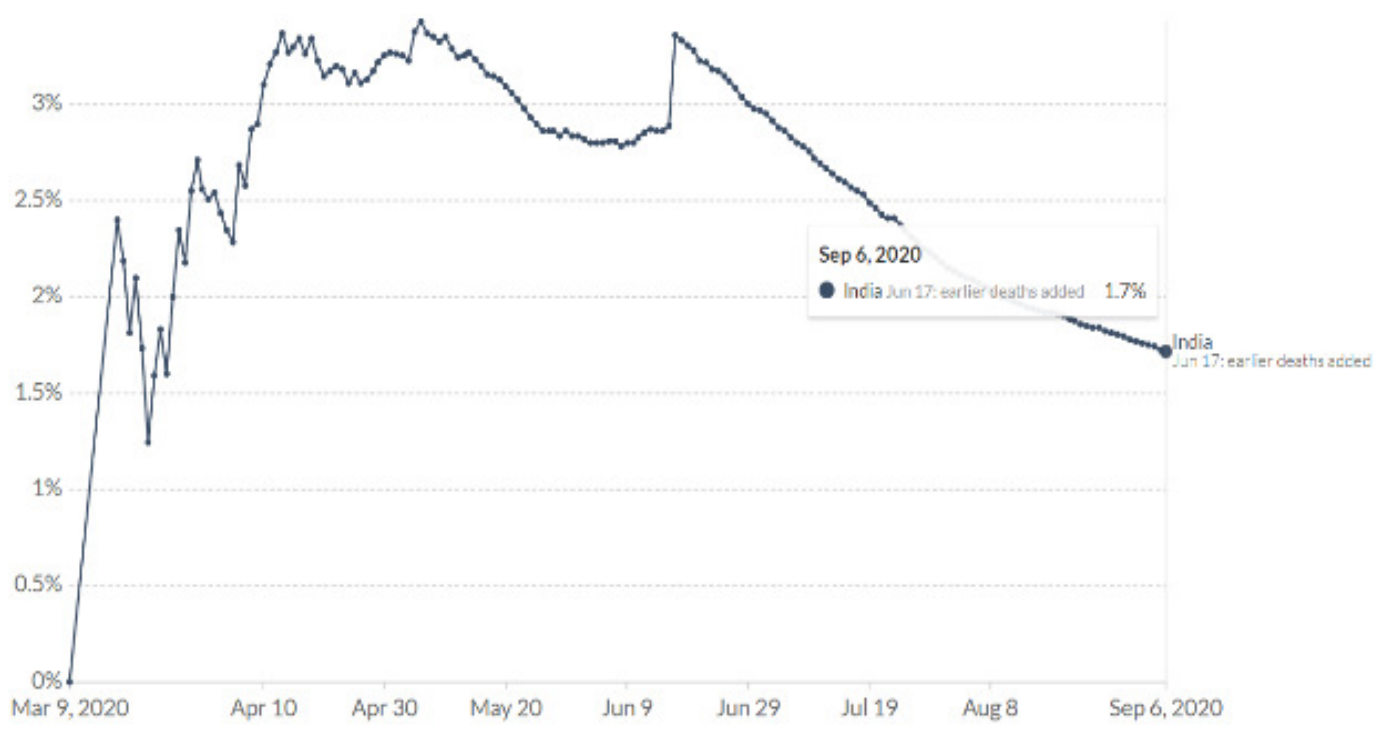




\section{Table $\mathbf{1}$ (on next page)}

Table 1

Clinical characteristics of cancer patients infected with COVID-19 according to outcome ( $\mathrm{N}=$ 186) 
Table 1. Clinical characteristics of cancer patients infected with COVID-19 according to outcome ( $N=$ 186)

\begin{tabular}{|c|c|c|c|c|}
\hline & $\begin{array}{l}\text { Total } \\
\mathrm{N}=186(\%)\end{array}$ & $\begin{array}{l}\text { Survivors } \\
n=159(\%)\end{array}$ & $\begin{array}{l}\text { Non-survivors } \\
n=27(\%)\end{array}$ & $P$ value \\
\hline \multicolumn{5}{|l|}{ Age (years) } \\
\hline Mean $\pm S D$ & $50.24 \pm 15.77$ & $50.22 \pm 15.66$ & $50.33 \pm 16.75$ & 0.974 \\
\hline Median (IQR) & $52(42-58.75)$ & $52(42-58.5)$ & $53(43.5-60)$ & 0.952 \\
\hline \multicolumn{5}{|l|}{ Gender } \\
\hline Male & $105(56.45)$ & $89(55.97)$ & $16(59.26)$ & 0.835 \\
\hline Female & $81(43.55)$ & $70(44.03)$ & $11(40.74)$ & \\
\hline \multicolumn{5}{|l|}{ Comorbidities } \\
\hline Present & $86(46.24)$ & $68(42.77)$ & $18(66.67)$ & 0.035 \\
\hline Absent & $100(53.76)$ & $91(57.23)$ & $9(33.33)$ & \\
\hline \multicolumn{5}{|l|}{$\begin{array}{l}\text { Number of comorbidities in a } \\
\text { patient }\end{array}$} \\
\hline No comorbidity & $100(53.76)$ & $91(57.23)$ & $9(33.33)$ & 0.004 \\
\hline Single & $47(25.27)$ & $41(25.79)$ & $6(22.22)$ & \\
\hline More than one & $39(20.97)$ & $27(16.98)$ & $12(44.44)$ & \\
\hline \multicolumn{5}{|l|}{ Type of comorbidities } \\
\hline Cardiovascular disease & $11(5.91)$ & $7(4.40)$ & $4(14.81)$ & 0.057 \\
\hline $\begin{array}{l}\text { Chronic obstructive pulmonary } \\
\text { disease }\end{array}$ & $2(1.08)$ & $2(1.26)$ & $0(0.00)$ & 1.000 \\
\hline Diabetes & $34(18.28)$ & $24(15.09)$ & $10(37.04)$ & 0.013 \\
\hline Hypertension & $45(24.19)$ & $36(22.64)$ & $9(33.33)$ & 0.233 \\
\hline Thyroid (Hypo/ Hyper) & $30(16.13)$ & $26(16.35)$ & $4(14.81)$ & 1.000 \\
\hline Other comorbidities & $5(2.69)$ & $3(1.89)$ & $2(7.41)$ & 0.154 \\
\hline
\end{tabular}




\begin{tabular}{|c|c|c|c|c|}
\hline \multicolumn{5}{|l|}{ Solid vs Hematological cancer } \\
\hline Solid & $153(82.26)$ & $133(83.65)$ & $20(74.07)$ & 0.274 \\
\hline Hematological & $33(17.74)$ & $26(16.35)$ & $7(25.93)$ & \\
\hline \multicolumn{5}{|l|}{ Cancer type } \\
\hline Brain & $2(1.08)$ & $2(1.26)$ & $0(0.00)$ & 0.095 \\
\hline Head and neck & $33(17.74)$ & $27(16.98)$ & $6(22.22)$ & \\
\hline Breast & $19(10.22)$ & $18(11.32)$ & $1(3.70)$ & \\
\hline Thoracic & $17(9.14)$ & $17(10.69)$ & $0(0.00)$ & \\
\hline Musculoskeletal and skin & $6(3.23)$ & $4(2.52)$ & $2(7.41)$ & \\
\hline Gastrointestinal & $40(21.51)$ & $31(19.50)$ & $9(33.33)$ & \\
\hline Genitourinary and gynecologic & $36(19.35)$ & $34(21.38)$ & $2(7.41)$ & \\
\hline Hematological & $33(17.74)$ & $26(16.35)$ & $7(25.93)$ & \\
\hline \multicolumn{5}{|l|}{ Cancer spread } \\
\hline Localized tumor & $58(31.18)$ & $52(32.70)$ & $6(22.22)$ & 0.361 \\
\hline Locally advanced & $78(41.94)$ & $67(42.14)$ & $11(40.74)$ & \\
\hline Metastatic & $50(26.88)$ & $40(25.16)$ & $10(37.04)$ & \\
\hline \multicolumn{5}{|l|}{$\begin{array}{l}\text { Cancer directed treatment } \\
\text { within } 1 \text { month of COVID-19 } \\
\text { infection }\end{array}$} \\
\hline Treated cases & $112(60.22)$ & $94(59.12)$ & $18(66.67)$ & 0.528 \\
\hline No treatment & $74(39.78)$ & $65(40.88)$ & $9(33.33)$ & \\
\hline \multicolumn{5}{|l|}{ Cancer treatment } \\
\hline Surgery & $31(16.67)$ & $27(16.98)$ & $4(14.81)$ & 1.000 \\
\hline Chemotherapy & $69(37.10)$ & $56(35.22)$ & $13(48.15)$ & 0.204 \\
\hline Radiotherapy & $21(11.29)$ & $20(12.58)$ & $1(3.70)$ & 0.320 \\
\hline Targeted therapy & $6(3.23)$ & $4(2.52)$ & $2(7.41)$ & 0.210 \\
\hline
\end{tabular}




\begin{tabular}{|c|c|c|c|c|}
\hline Immunotherapy & $11(5.91)$ & $10(6.29)$ & $1(3.70)$ & 1.000 \\
\hline \multicolumn{5}{|l|}{ Severity of COVID-19 infection } \\
\hline Mild & $134(72.04)$ & $125(78.62)$ & $9(33.33)$ & $<0.00001$ \\
\hline Moderate & $43(23.12)$ & $32(20.13)$ & $11(40.74)$ & \\
\hline Severe & $9(4.84)$ & $2(1.26)$ & $7(25.93)$ & \\
\hline $\begin{array}{l}\text { Patients who } \quad \text { received } \\
\text { ventilator support }\end{array}$ & $12(6.45)$ & $0(0.00)$ & $12(44.44)$ & 0.000 \\
\hline
\end{tabular}

1 


\section{Table 2 (on next page)}

Table 2

Logistic regression analysis (univariate) and odds ratio for death in the cohort ( $N=186$ COVID-19 infected cancer patients) 
1 Table 2. Logistic regression analysis (univariate) and odds ratio for death in the cohort ( $N=186$

2 COVID-19 infected cancer patients)

\begin{tabular}{|c|c|c|c|}
\hline Variable & Odds ratio & $95 \% \mathrm{Cl}$ & $P$ value \\
\hline Age & 1.00 & $0.97-1.03$ & 0.974 \\
\hline Gender (male vs. female) & 1.14 & $0.49-2.62$ & 0.750 \\
\hline Comorbidity & 2.68 & $1.13-6.32$ & 0.025 \\
\hline Comorbidity (multiple vs. single) & 3.01 & $1.02-9.07$ & 0.047 \\
\hline Cardiovascular disease & 3.77 & $1.02-13.91$ & 0.046 \\
\hline Diabetes & 3.31 & $1.35-8.09$ & 0.009 \\
\hline Hypertension & 1.71 & $0.71-4.13$ & 0.234 \\
\hline Thyroid (hypo/ hyper) & 0.89 & $0.28-2.79$ & 0.841 \\
\hline Other comorbidities & 4.16 & $0.66-26.15$ & 0.129 \\
\hline $\begin{array}{l}\text { Hematological malignancies vs. } \\
\text { solid tumors }\end{array}$ & 1.79 & $0.69-4.67$ & 0.233 \\
\hline Head and neck & 1.40 & $0.51-3.79$ & 0.511 \\
\hline Breast & 0.30 & $0.04-2.36$ & 0.253 \\
\hline Musculoskeletal and skin & 3.10 & $0.54-17.82$ & 0.205 \\
\hline Gastrointestinal & 2.06 & $0.85-5.03$ & 0.111 \\
\hline Genitourinary and gynecologic & 0.29 & $0.07-1.30$ & 0.107 \\
\hline Advanced vs. localized cancer & 1.42 & $0.50-4.10$ & 0.514 \\
\hline Metastatic vs. localized cancer & 2.17 & $0.73-6.46$ & 0.166 \\
\hline Cancer treatment & 1.38 & $0.58-3.27$ & 0.460 \\
\hline Surgery & 0.85 & $0.27-2.66$ & 0.780 \\
\hline Chemotherapy & 1.71 & $0.75-3.88$ & 0.202 \\
\hline Radiotherapy & 0.27 & $0.03-2.08$ & 0.208 \\
\hline Targeted therapy & 3.10 & $0.54-17.82$ & 0.205 \\
\hline Immunotherapy & 0.57 & $0.07-4.67$ & 0.603 \\
\hline
\end{tabular}




\begin{tabular}{|l|l|l|l|} 
Mild COVID-19 infection & 0.14 & $0.06-0.33$ & $<0.0001$ \\
Severe COVID-19 infection & 2.72 & $1.15-6.45$ & $\mathbf{0 . 0 2 2}$ \\
& 27.48 & $5.34-141.49$ & $<0.001$ \\
\hline
\end{tabular}

3

4 Note: For the categorical variables where the comparison group is not indicated absence was 5 taken as the reference.

6

7 


\section{Table 3(on next page)}

Table 3

Multivariate logistic regression analysis and risk of death in the cohort ( $\mathrm{N}=186$ COVID-19 infected cancer patients) 
1 Table 3. Multivariate logistic regression analysis and risk of death in the cohort ( $N=186$ COVID-

219 infected cancer patients)

3

\begin{tabular}{|l|c|c|c|}
\hline Variable & Odds ratio & $95 \%$ Cl & P value \\
\hline Age & 0.99 & $0.96-1.02$ & 0.403 \\
Comorbidity & 3.16 & $1.16-8.61$ & $\mathbf{0 . 0 2 4}$ \\
Chemotherapy, Yes/ No & 1.63 & $0.64-4.15$ & 0.301 \\
Radiotherapy, Yes/ No & 0.19 & $0.02-1.59$ & 0.126 \\
Targeted therapy, Yes/ No & 2.70 & $0.42-17.37$ & 0.296 \\
Surgery, Yes/ No & 0.87 & $0.25-2.94$ & 0.819 \\
\hline
\end{tabular}

4

5

6 